Rebecca Henn | Caldieron, Miller | Constance Bodurow Stallmeyer, Dearborn | Seth Wiley | Brian Szymanik

\section{Green Measures... or, none of us are green until all of us are green}

\author{
by: Brian Szymanik, AIA, LEED AP BD+, Brian Szymanik \\ Architects
}

\begin{abstract}
This paper introduces a re-consideration of the tenets of the 'triple bottom line' (economy, environment, and society) to contemplate the societal implications of the current successes enjoyed by the environmentallysensitive design movement. Considering the tools that we use to gauge the successes of sustainable ambitions, this work proposes the ways in which we apply sustainable design metrics are fundamentally working against the tenets of the triple bottom line. When considered through the lens of society, and in particular the urban poor, the current trajectory of the sustainable design movement is one that may create voids where a sustainable urban future can not exist.
\end{abstract}

\section{Visioning Sustainable Urban Futures}

Ask anyone what "Green" or "Sustainable" design entails, and you are likely to get as many different answers as the number of people you ask. Attempts to precisely define or quantify sustainability will uncover quickly the sheer complexity of the emerging field of sustainable design and the wide range of issues, disciplines, and concerns that it must address in its efforts to realize a more sustainable future. While it is safe to say there is no one all-encompassing strategy for defining this term or realizing its vision, many organizations have acknowledged that for any endeavor to be truly sustainable, it must address at least three broad considerations: financial performance, environmental impact, and societal effects. One such organization is the US Green Building Council (USGBC), the preeminent authority on green construction in the built environment in the United States. This organization has spearheaded the implementation of green building strategies in the design and construction industries through its flagship Leadership in Energy and Environmental Design (LEED) building certification program. Both the USGBC and LEED operate on a series of guiding principles that include:
1. Promote the Triple Bottom Line.
2 .Establish Leadership.
3 .Reconcile Humanity with Nature.
4 .Maintain Integrity.
5 . Insure Inclusiveness.
6 .Exhibit Transparency.
7. Foster Social Equity.

In considering the goals and mission of the sustainable design movement, the 'triple bottom line' has been developed as a model to measure the success of any endeavor in terms of its impact on people, the planet, and profit. First developed as a way for corporations to take full account of the costs of doing business, the triple bottom line has become a key component of the sustainable design movement due, in part, to its success in quantifying societal and environmental impacts at a scale (and in a language) that speaks well to the economic concerns of most endeavors.

The triple bottom line has historically been used to provide a defense for more sensitivity in the design of the built environment in response to a growing concern over a mounting ecological crisis. Over the past few decades, more and more people have come to believe that the global concerns of the climate crisis are real, and advancing by the year. The ecological design movement has been transparently and effectively advancing its agenda by making convincing, documentable, and datadriven projections towards the economic viability of more sustainable futures. In terms of the triple bottom line, the argument posits that sustainable design isn't just the right thing to do, but it is the smart thing as well. This tactic has brilliantly almost eliminated the question of "why should we bother with a sustainable design?" through a concerted campaign to educate the broader public on both the causes of the crisis and the role that sustainable design can play in its future.

Interestingly, we are now finding that the conversation in the milieu of a post-2008 world is shifting in a direction that seems to privilege the economic conditions of a green endeavor as much as, if not more than, the environmental implications that had led the discussion just a few years ago. President Obama is actively promoting "clean energy, not only as the path to the future but as the key to economic revival. 'To truly transform our economy, protect our security, and save our planet from the ravages of climate change, we need to ultimately make clean, renewable energy the profitable kind of energy.'" Since the onset of the Great Recession, 'Green' design has started to be advanced within the political realm as synonymous with economic recovery. While there is certainly a healthy debate on the merits of the argument, the conversation has entered the national discourse as an economic concern. This is no longer a dialogue about a moral imperative that takes place on the fringe, but is now advanced as a conversation about an economic generator at national, regional, and local scales in the United States. 
Throughout all of this debate, it seems that the societal impact of our decisions may be getting lost while the seemingly more pressing economic crisis draws more and more attention. Now, as sustainable design has entered the national conversation, seems to be the time to reconsider once again (in an amount proportionate to the economic and environmental concerns of our work) the social impact of the policies, procedures, and processes we utilize to realize our visions of a more sustainable future.

\section{Not-for-Profit Economies}

Clearly, in practice, the economic concerns of any development drive the ambitions of a building project. In considering the economics of building, the application and impact of sustainable design has been studied and evaluated at length. Generally speaking, sustainable design more than pays for itself over time. In a report detailing "The Costs and Financial Benefits of Green Buildings," California's Sustainable Building Task Force found that,

"While the environmental and human health benefits of green building have been widely recognized, this comprehensive report confirms that minimal increases in upfront costs of about $2 \%$ to support green design would, on average, result in life cycle savings of $20 \%$ of total construction costs -- more than ten times the initial investment. For example, an initial upfront investment of up to $\$ 100,000$ to incorporate green building features into a $\$ 5$ million project would result in a savings of $\$ 1$ million in today's dollars over the life of the building."

Although studies point to these economic rewards, the underlying assumption is that there is capital available to spend on this endeavor. Like much in life, you need money to save money. When considered through the eyes of an organization that is working to better the public good within modest means, this presents a dilemma. Organizations that depend on good will, or public support, to fund their missions, often have fewer resources at hand for their work than private, for-profit outfits. Modest means call for more efficient operations, yet more efficient operations require more capital at the onset of a project. The 'chicken and egg' scenario runs rampant through the non-profit realm. Clearly, these outfits are among those that would benefit most from the efficiencies provided by more sustainable design solutions, yet sustainable design often remains just out of reach. Non-profits, non-governmental organizations (NGO's), and community-based organizations often operate hand-tomouth taking every dollar acquired and putting it immediately into the programs they have built to serve their missions. Historically, non-profits that are embarking on a development project to house their programs are confronted with a choice to either spend more money to increase the efficiencies of their operations, or to dedicate those resources to the programs that serve their broader mission. In human terms, the question often becomes "do you save the lives of a small number of people today, or do you strengthen the operations of your organization over the next 20 years to save many more lives tomorrow?" Both are concerns that weigh heavily on community leaders, and a seemingly impossible decision to face.

Obviously, any discussion of the economics of green building must take into account first costs and life-cycle costs of buildings. In considering the first costs of green construction over the past twenty years, a notion has developed within the design and construction industries that green building is more expensive than conventional construction. In the earliest days of the environmentally-sensitive design movement, this was certainly the case. Early supporters served as patrons of the movement funding the education, research, and trials that architectural firms, material suppliers, and builders were testing in the field. As sustainable design has evolved into a discipline, the industry has ascended the learning curve associated with green building while novel means and methods of construction have become standards. In practice, the cost of building green (to those that have navigated the system) has come down as participants familiarized themselves with the nuances of more sustainable building practices.

\section{Green Metrics: A Recipe for Sustainability}

Interestingly, as these costs have become less onerous, other pressures have exerted themselves on the budgets of sustainable developments. As an industry still in its relative infancy, the sustainable design field found itself confronted with two problems: complexity and accountability. Any building project that strives towards a sustainable solution will have a large variety of competing requirements (budget, schedule, energy use, orientation, access, site logistics, performance, etc.) that must be negotiated to arrive at the most sustainable solution available. Additionally, once measures are employed, the building must perform to the ambitions set forth at the onset of the project. Beginning in the early 1990's a number of rating systems (LEED in the US, BREEAM in the UK, among others) were developed across the globe to respond to these issues. As the green building industry has evolved and grown more complex, these varied metrics have taken a more prominent role in the field expanding their reach to include more than 600 different measurement systems. For many, these metrics have come to be synonymous with "Green Building" or "Sustainable Design."

Although the means and methods vary, most rating systems share a common agenda to "cover and assess all the aspects of sustainability that are relevant to buildings." They also share a common device: the checklist, a predetermined recipe for sustainability. Checklists are wonderful tools that operate on the "fundamental principle (that) what you measure is what you get, because what you measure is what you are likely to pay attention to." If we are only paying attention to the measure, the impact and outcomes of what we are designing may be unanticipated in a variety of ways. The danger in checklists is they often run the risk of becoming more than benchmarks, they can-and have- 
become processes in and of themselves. When a metric becomes a process, it assumes that the author of the checklist has addressed all of the issues relevant to the list at hand. If that is not the case, then we are faced with a misdirected sequence of solutions that could be contributing to unanticipated problems while meeting or exceeding the limits of the standard of measurement in question. In other words, we could meet and exceed all of the components of the rating system standard and still be designing a future that is unsustainable, if the metric is off-target.

While many engage the practice of sustainable design in a rigorous and critical process, there are those that see point acquisition and the metrics of the rating system as THE measure of success. This comes as no surprise given the complexity any sustainable project and the relative ease and speed with which some have entered the market for sustainable design through a system that allows testing as a means to prove expertise in the field. Like any benchmark that standardizes the complexities of an endeavor into a test that measures core competencies rather than true experience in the field, passing the test is often considered to be the true measure of expertise. But, these professionals are not necessarily experts in sustainable design, but rather in the measures through which sustainable design is gauged. While seemingly synonymous, these are vastly different areas of expertise. It is a beautiful model, fraught with contradictions.

When constituents begin to say that they have developed a LEED Certified Building (for example) rather than a sustainable building design, we need to pause and re-consider the ambitions of the sustainable design community, to critically contemplate the impact of engaging metrics as a process, and to work diligently to unveil the contradictions and unintended outcomes that may occur when the lines between design processes and measurement systems tangle in knots that may be imperceptible to some.

\section{More Sustainable Futures, for whom?}

Looking back to the Guiding Principles of the USGBC, it certainly seems safe to assume that the LEED Checklists would be adequately addressing economic factors, environmental stewardship, and societal concerns. But, are they? If we fulfill all of the requirements of LEED as a system or process, will a more sustainable future be the result of our hard work?

In terms of economic concerns and environmental stewardship, LEED certainly seems to be living up to its promise. As previously mentioned, years of data-driven analysis and careful study have proven this to be the fact. But, the social impact and import of these works has not yet been subjected to the same rigorous analysis. The LEED program - in each of its iterations - strives to provide accommodations for socially responsible components within a development, but does not reward (or consider) the social impact of that development on its surrounding community. If we look to the LEED for Neighborhood Development Rating System as an example, there are categories that consider Mixed Income Access (NPD Credit \#4), Access to Civic and Public Space (NPD Credit \#9), Access to Recreation Facilities (NPD Credit \#10), and Community Outreach and Involvement (NPD Credit \#12). While each of these metrics seek to promote socially equitable and engaging communities by addressing physical and mental health through the amenities offered, there are no accommodations made for developments that operate in service of the conditions that these categories seek to promote.

This raises a series of interesting questions about access, ambition, and intent. For whom do we intend to develop more sustainable urban futures? Is sustainability the purview of those who live and work in LEED Certified Buildings, or does it belong to all? Is a more sustainable future a right or a privilege? Until recently, it seems that sustainable design was neither, but was a method employed by those who were passionate about mitigating the environmental implications of their work. Historically, it has been a moral imperative for those that sought to advance its agenda and goals. As sustainable design has taken a foothold in the national dialogue of economic recovery, the conversation seems to be evolving into one where sustainable ambition is a national mandate and seemingly an evolving right for us all. As the national and global responses to the economic and climate crises have started to indicate, the only tenable future is a sustainable one. Governments across the world seem to be aligning in a common agenda to reduce energy consumption and increase the efficiencies of their infrastructures at an unprecedented scale. If we look to the United Kingdom for a case study, we see the marriage of regulatory constraints and sustainable design metrics touted as a great success.

In terms of quantity, the U.K.'s BREEAM system eclipses all others. "The high figure of around 115,000 certified and over 800,000 registered buildings (as of 2009) for BREEAM is due, in part, to the fact that the British Government has introduced regulations and standards for sustainable building in Great Britain, which are based on the BREEAM requirements. Mention should be made here of the 'Sustainable Procurement Action Plan,' which was passed in 2006, and which requires that all new state buildings and all renovations of such buildings should meet the BREEAM Excellent Standard. Also the legal regulation 'The Code for Sustainable Homes,' introduced in May 2008, requires that certain predetermined sustainability goals be met for all new housing, and that these buildings should be assessed upon completion. At present the main focus of BREEAM certification is clearly on housing construction, as the number of assessments up to the year 2008 clearly shows: in the area of housing construction 109,450 dwelling units have been certified to date, in the area of non-housing construction only 1,358 buildings."

As governments begin to codify green building systems and require certain benchmarks be met in the construction and rehabilitation of the 
built environment, it is apparent that architects will need to consider sustainable design methodologies more prominently in their work processes. As they do, It is important to contemplate the role of the architect in the actualization of sustainable ambitions. Fundamentally, in the eyes of the law, the practice of architecture is concerned with the protection of the health, safety, and welfare of the public. Architects serve their clients, and protect the public during the course of their work. There is, and always has been, a social component to the responsible practice of architecture. When we consider this mandate in terms of the Architect's role in the sustainable design process which LEED measures, it calls into question the true mandate of the metric. Who does LEED serve, what does LEED protect? According to the U.S. Green Building Council (USGBC), "Participation in LEED gives building owners and owners the tools they need to have an immediate and measurable impact on their building's performance." It is a check and balance system to insure that the design, construction, and ownership teams involved in a sustainable project are all working in concert to achieve a certain level of compliance with the system. It allows funding agencies, owners, the general public, and other interested parties the opportunity to understand the success of a project in achieving different levels of efficiency, environmental sensitivity, and resource reduction. But, in the end, it is a self-perpetuating system that is only responsible to itself. The integrity of the rating system is sacred, like all metrics - it must be consistent and unwavering. While occupants of LEED Certified Buildings certainly enjoy the benefits of lower operating costs, reduced waste, conservation of resources, and healthier and safer environments, their health, safety and welfare is not the foremost concern of the rating system. These concerns remain the purview of the architect as they fulfill their charge to protect the health, safety, and welfare of their communities.

But what about the communities that architects are charged to protect? How will they bear the burden of certification if or when sustainable design becomes not an option, but a requirement? As previously discussed, the construction costs of building sustainably are increasingly becoming more affordable. But the cost of proving that you have employed sustainable strategies remains formidable. The expense of certification through the rating systems' coordinating agencies varies greatly, but all add considerable expense to the achievement of a sustainable ambition. As an example, consider the US Green Building Council's (USGBC) LEED metric, "The total fees for LEED-NC start at US\$3,400 and end at a maximum sum of US\$25,900 for members [of the US Green Building Council] (based on a separate review performed after each the design and construction phase)." Additionally, the design team exerts a great deal of effort in, and requires a commensurate fee for, preparing a submission to the Green Building Certification Institute (GBCl), a third-party certification agency, documenting and asserting that these strategies have indeed been implemented. The act of documenting the steps taken to meet the requirements of the checklist can add tens of thousands of dollars to the total cost of certification. Excluding construction cost increases, and only considering fees collected by the certifying agency and the design team, the additional cost borne for certification alone could easily amount to tens of thousands of dollars, for even small-scale projects. On profit-driven developments, owners have the opportunity to pass this cost onto their users in the form of higher rents, more substantial sale prices, or by manipulating profit margins in their favor. In the non-profit realm, what happens when there is no opportunity to pass this additional cost onto an end user? Either the programs offered, space allotted per user, or other administrative considerations will be sacrificed to meet what is now a code requirement, not a moral dilemma as outlined above. When considered through the societal lens of the triple bottom line, this money may be essentially misdirected when spent by non-profit groups that operate in service of their communities. The logic of the triple bottom line is cast aside when environmentally sustainable strategies are privileged over social concerns. Much like the profit-driven model that the environmentally-sensitive design movement grew in reaction to, we now see the scales swinging from planet to profit, leaving some members of society behind. As architects, the responsibility to serve and protect remains in our hands.

The examples offered thus far identify the issues at hand in the perspective of a single organization and the dilemmas they face in building more sustainable futures for their constituents. However, when considered at the scale of the entirety of non-profit organizations operating in the U.S. alone, the matter compounds itself to be one of national concern. With tens of thousands of community-based organizations in the United States, the ways in which we dispense sustainability could make, or break, the futures of many of these organizations. If we, as a society, commit to the stance that sustainable futures are a right of all citizens, the conversation will necessarily need to shift from one of right or privilege to a discussion about the equitable deployment of this new infrastructure in our cities and suburbs.

To be clear, in the United States there is no published plan to incorporate the benchmarks of the LEED rating system into any model building code. However many funding sources are beginning to require certification of sustainable measures as a baseline requirement for acquisition of monetary assistance for non-profits engaged in the service of their communities. As an example, in the State of Pennsylvania, affordable housing developments funded by the Pennsylvania Housing Finance Agency commit during pre-design application phases to meet or exceed a number of measures intended to increase the efficiency of buildings and reduce future operating costs for landlords and residents. Other examples include Enterprise's Green Communities Program which employs similar strategies to "deliver significant health, economic, and environmental benefits to low-income families." Finally, the Clinton Climate Initiative also uses funding to advance a net-zero energy agenda where feasible and appropriate to the project under consideration. 
Beyond the commercial real estate market, we should also begin to examine the ramifications of these policies to the already-stressed housing infrastructure of the United States. As additional sustainable measures become required by building and zoning codes, the urban poor will likely find themselves in a similar situation to the plight of nonprofits discussed above. Entire districts that are already in distress in our cities could find themselves without access to the benefits of what seems to be an evolving right to the new green economy. The World Health Organization Commission on Social Determinants of Health has acknowledged that urban poverty is a "critical pathway to ill health and health inequities." Additionally, urban poverty is not just an economic condition, but also one that is exacerbated by social, political, and environmental concerns.

"Much of urban poverty is not because of distance from infrastructure and services but from exclusion. (People) are excluded from the attributes of urban life that remain a monopoly of a privileged minority - political voice, secure good-quality housing, safety, and the rule of law, good education, health services, decent transport, adequate incomes, access to goods and services, credit - in short, the attributes of full citizenship."

To avoid repeating past mistakes in the distribution of infrastructures (food, wealth, public transportation, education, etc.) across the nation, it is imperative that the deployment of sustainability accommodate pathways that allow access to this system for the nation's marginalized communities and their constituents. Nowhere else would the benefits of healthier environments, reduced energy consumption, minimized operating costs, longevity of systems and materials, and the efficient use of available resources be more widely beneficial than in the service of society's most in need.

Unfortunately, the path we are currently traveling seems to exclude many from this new infrastructure. Access to the rating systems we use to measure sustainable endeavors is based on a profit-driven model that seeks to operate within a traditional supply and demand marketplace. In theory, the rating system is available to anyone willing, and able, to incur the costs of certification. Whether required by regulatory agencies or as a condition of funding, sustainability is viewed currently as an economic asset. Years of transparent, data-driven analysis has proven just how valuable sustainable design can be, and in the supply / demand model this makes perfect sense. However, as the conversation moves from economic viability to that of an entitlement of each citizen, the metrics and models we employ need to be re-calibrated to accommodate this shift in focus. Studies have concluded that "sustainable urban development functions only when economic growth, social cohesion and justice as well as the elimination of social segregation work together as equal partners." The current methods and metrics employed can not support equal access to all members of society. Some constituencies simply are not able to bear the costs incurred by the system. When cost becomes an impediment to access, the system leaves people behind and social inequity is a result. When one person is left out of the equation, it is a concern. When entire populations can not gain access, it is a fundamental flaw in the practice of sustainability. If entire populations are not gaining access, what will the new green infrastructure we are promoting look like? How will it act?

There is no doubt that the intentions of the Sustainable Design movement are noble. The ambitions of this project over the past 50 years began in a manner that weighed equally the needs of business, the environment, and the general citizenry in an effort to enact a more sustainable future for us all. Since the earliest days of this campaign, its proponents have argued that no one factor can or should measure the sustainability of any endeavor. Its greatest success has been convincing the world that people, profit, and the planet each bear an equal share of the responsibility and reward in realizing a more sustainable future. Now, as the successes of the past 50 years take root at an unparalleled scale, is the time to recalibrate and insure that the path, metrics, and ambitions we employ act together in a concerted effort that excludes no one and allows equal access to the nation's burgeoning green infrastructure. Is our future one that is just, one that is equitable, and one that realizes the social, cultural, and environmental ambitions on which the sustainable design movement was founded? If so, we are on the right track. If not, now is the time to correct our course.

\section{A CASE STUDY: Connelly House, Philadelphia, PA. Measuring Social Impact, "None of us are home until all of us are home."}

For a moment, let's consider the practical application of LEED in a development that not only seeks to provide socially responsible amenities in its projects, but also - through its work - strives to have a positive impact on the world in which it is situated. In Philadelphia, two organizations - Project H.O.M.E. and The Bethesda Project - have been tireless in their fight for social equity, political advocacy, and housing access. Using development of the built environment as a vehicle to foster social justice, support distressed communities, and empower underserved populations, Project H.O.M.E. and the Bethesda Project recently joined together to develop a supportive housing facility, named the Connelly House, for recently homeless men and women in the urban business district of Center City Philadelphia. Surrounded by luxury condominiums, office towers, shopping venues, and all of the amenities available in the core of a thriving city, this rental apartment building provides 79 units of subsidized affordable housing in the form of efficiency apartments and single room occupancy (SRO) units. The 63,620 square foot building is outfitted with communal spaces intended to nurture the physical rehabilitation and mental well-being of residents with support systems desperately needed after years spent on the street. These spaces include social services program offices dedicated 
for resident use, communal kitchens to encourage the development and strengthening of social bonds between residents, exercise rooms to promote physical activity and health, and a generous (by supportive housing standards) lobby to welcome residents and visitors to this new home for the recently homeless.

Like much of Project HOME and the Bethesda Project's work, this project was developed to promote stewardship at multiple scales (the individual, the community, and the environment). First and foremost, the project sought to help men and women end the cycle of homelessness in their own lives and live a life of human dignity. These individuals now have a support system in place that actively addresses their needs and provides a path that encourages active engagement with the world. Considering the immediate community surrounding the site, this project is unique in that affordable housing often isn't located in high-rent affluent districts in cities. Like many urban cores, Center City Philadelphia has a constant population of homeless men, women, and families. Where other cities have sought to relocate the homeless to far flung districts surrounding the city's center, this project intends to provide care, support and rehabilitation to people suffering in the district with the broader support of the community-at-large. It is a fantastic opportunity to advance the missions of the owner's organizations, to increase the visibility of the services these groups offer, and to call attention to the plight of a population so often overlooked in the day-today life of the city.

In order to realize this ambition, the project team needed to develop fiscally responsible solutions to formidable site constraints, building performance issues, and environmentally-sensitive ambitions in both its construction costs, and perhaps more importantly, in its operational expenses over the life of the building. As is the case with most projects that rely on donations and public funding for support, it is imperative that donated funds be spent wisely and in ways that advance the impact of the project's programs for the people it serves. Sustainable design as a strategy to meet these goals, and LEED Certification as a documentable way to insure performative requirements were met, was a logical and necessary solution. In this situation, LEED became a fundamental tool to advance the goals of the project using sustainable design, and the metric that gauges it, to support, augment, and improve the quality of life of the future residents of the Connelly House. Interestingly, LEED - and its brand recognition - brought additional interest and funding to the project allowing the team to add amenities and to target Silver Level Certification, rather than the original ambition to simply certify the building. Currently, the building falls just two points shy of achieving LEED Gold Certification, a substantial accomplishment for any development, but especially so for one that relies on good will and public support to advance its mission and meet its goals.

Curiously, this project that has provided permanent supportive housing for 79 recently homeless men and women has not received a single point for the people it has saved, the community that it is building, or the lives it is stitching back together. It has spent a significant amount of money to document the sustainable design measures it put in place to support a better quality of life for its residents. Admittedly, it has gained much from engaging LEED as a metric and unintentional fundraising device, but how much more good could have been done in support of its programs with the money that is being spent on LEED Certification? By rough estimates, the costs of pursuing LEED Certification could have funded an additional 250 square feet of residential space, the equivalent area of a single SRO unit. Another life rebuilt, another person off the street, another opportunity to serve as stewards to those who have no one else to turn to, or a fee submitted for services rendered? It is here, at the practical application of LEED as a measure, where the ambitions of the USGBC, GBCl, and sustainable design movement crumble in response to the mandates of the rating system. If you pull back from the minutia of the LEED Checklist and ask a few simple questions, the dilemma becomes clear. "Does this project create a more sustainable milieu for its residents, community, and city?" The simple answer is yes. Next question, "Does this project not only meet, but also advance the guiding principles through which LEED was developed?" Again, the simple answer is yes. Final question, "Does it do so in a way that deserves special recognition, or accommodation, to reward its impact on society?" Again, I would argue it does. When we look at sustainability in the built environment, the metrics we use to gauge success can not just measure the built, quantifiable components that are constructed around us. They must also look at the life of a building and measure all of its impacts. One of the fundamental presuppositions of the sustainable design movement is the need for each of us to take personal responsibility for the world around us. The social impact of our work deserves as much credit as the environmental impact that green building rating systems currently measure so well. As a device intended to make transparent the impact that sustainable design will have on the world around us, LEED must provide mechanisms that make accommodations for those projects that advance the social ambitions of its mission if the USGBC hopes to realize a more sustainable future for us all.

\section{Endnotes}

1. Ebert, Ebig, and Hauser. DETAIL. page 6.

2. USGBC Online. "Guiding Principles."

3. Hindle, "Idea: Triple Bottom Line."

4. Green. "The Elusive Green Economy"

5. Katz, et al. "The Costs and Financial Benefits of Green Buildings."

6. Ebert, Ebig, and Hauser. DETAIL. page 26.

7. ibid., page 24.

8. Schoof. "DETAIL Green"

9. Hindle, "Idea: Triple Bottom Line."

10. USGBC Online. "LEED 2009 for Neighborhood Development Rating System."

11. Ebert, Ebig, and Hauser. DETAIL. page 25-26. 
12. USGBC. online. "What LEED Delivers."

13. Ebert, Ebig, and Hauser. DETAIL. page 44.

14. Enterprise Online. "Enterprise Green Communities Criteria."

15. Susan Mercado, et. al. "Urban Poverty: An Urgent Public Health Issue."

16. Ebert, Ebig, and Hauser. DETAIL. page 11.

\section{References}

Contal, Marie-Helene and Revedin, Jana. Sustainable Design: Toward a New Ethic in Architecture and Town Planning. (Basel: Birkhauser, 2009).

Ebert, Thilo, Ebig, Natalie, and Hauser, Gerd. DETAIL Green Books: Green Building Certification Systems. (Munich: Institut fur internationale Architektur-Dockumentation GmbH \& Co. KG, 2011).

Enterprise, Online. "Enterprise Green Communities Criteria." http:// www.enterprisecommunity.com/solutions-and-innovation/enterprisegreen-communities/criteria. (30 December 2011).

Green, Joshua. "The Elusive Green Economy," The Atlantic Magazine. July/August 2009.

www.theatlantic.com/magazine/archive/2009/07/the-elusive-greeneconomy/7554/ (20 September, 2011).

Hindle, Tim. "Idea: Triple Bottom Line," The Economist, online; November 17, 2009, www.economist.com/node/14301663/print (29 September, 2011).

Kats, Gregory et al. "The Costs and Financial Benefits of Green Buildings: A Report to California's Sustainable Building Task Force." Report developed for the California Sustainable Building Task Force, October 2003. www.ciwmb.ca.gov/GreenBuilding/Design/CostBenefit/ Report.pdf (17 October 2011).

Leatherbarrow, David. Uncommon Ground: Architecture, Technology, and Topography. Cambridge, MA: The MIT Press, 2000.

Marras, Amerigo. ECO-TEC Architecture of the In-Between. New York: Princeton Architectural Press, 1999.

McLennan, Jason F. The Philosophy of Sustainable Design. Kansas City, MO: Ecotone LLC., 2004.

Mercado, Susan, Havemann, Kirsten, Sami, Mojgan, and Ueda, Hiroshi. "Urban Poverty: An Urgent Public Health Issue." The New York Academy of Medicine with The National Center for Biotechnology Information. www.ncbi.nlm.nih.gov/pmc/articles/PMC1891652/ (28 September, 2011).

Schoof, Jakob. ed. DETAIL Green English Edition, 02/2009.

USGBC Online. "2009 LEED for Neighborhood Development Rating System." http://www.usgbc.org/ShowFile.aspx?DocumentID=9907. (04 January, 2012).
USGBC online. "What LEED Delivers." http://www.usgbc.org/ DisplayPage.aspx?CMSPagelD=1990. (02 January, 2012).

USGBC Online. "Guiding Principles." http://communicate.usgbc.org/ usgbc/2006/08.15.06_guiding_principles/guidingPrinciples/. 